\title{
Promoter methylation of Raf kinase inhibitory protein: A significant prognostic indicator for patients with gastric adenocarcinoma
}

\author{
DONG-XIA LI ${ }^{1}$, HAI-YANG CAI ${ }^{1}$, XIA WANG $^{2}$, YAN-LING FENG $^{3}$ and SONG-WANG CAI ${ }^{4}$ \\ ${ }^{1}$ School of Basic Medical Sciences, Xinxiang Medical University, Xinxiang, Henan 453003; ${ }^{2}$ The First Affiliated Hospital of \\ Xinxiang Medical University, Weihui, Henan 453100; ${ }^{3}$ Department of Pathology, Public Health Clinical Center of \\ Fudan University, Shanghai 201508; ${ }^{4}$ Department of Cardiothoracic Surgery, Third Affiliated Hospital, \\ Sun Yat-sen University, Guangzhou, Guangdong 510630, P.R. China
}

Received February 8, 2014; Accepted June 20, 2014

DOI: $10.3892 /$ etm.2014.1833

\begin{abstract}
DNA methylation has an important role in the development of carcinomas. As a metastasis suppressor gene, Raf kinase inhibitory protein (RKIP) suppresses tumor cell invasion and metastasis. In the present study, the associations between RKIP protein expression and promoter methylation with clinicopathological parameters, prognosis and survival rates in gastric adenocarcinoma were investigated. RKIP protein expression and promoter methylation were measured in 135 cases of surgically resected gastric adenocarcinoma specimens and corresponding normal tissues using immunohistochemistry and methylation-specific polymerase chain reaction, respectively. Kaplan-Meier analyses were performed to analyze the patient survival rate. Prognostic factors were determined using multivariate Cox analysis. RKIP promoter methylation was detected in $48.9 \%$ of gastric carcinoma tissues and $5.17 \%$ of adjacent tissues $(\mathrm{P}<0.05)$. RKIP protein expression was detected in $43.0 \%$ of gastric carcinoma tissues and $91.1 \%$ of adjacent tissues $(\mathrm{P}<0.05)$. The protein expression levels and promoter methylation of RKIP were shown to correlate with pathological staging, Union for International Cancer Control-stage, tumor differentiation and lymph node metastasis $(\mathrm{P}<0.05)$. In addition, the protein expression of RKIP in gastric carcinomas was demonstrated to be associated with promoter methylation of RKIP. Survival analysis of gastric carcinoma patients revealed that promoter methylation in RKIP-positive tumors correlated with a significantly shorter survival time when compared with RKIP-negative tumors
\end{abstract}

Correspondence to: Dr Song-Wang Cai, Department of Cardiothoracic Surgery, Third Affiliated Hospital, Sun Yat-sen University, 600 Tianhe Road, Guangzhou, Guangdong 510630, P.R. China

E-mail: songwangcai@yahoo.com

Key words: Raf kinase inhibitory protein, methylation, gastric adenocarcinoma, prognosis
$(\mathrm{P}=0.0002$, using the log-rank test). Using multivariate Cox analysis, promoter methylation of RKIP was shown to be an independent prognostic factor $(\mathrm{P}=0.033)$. These results indicated that abnormal promoter methylation of RKIP may be one cause of downregulated RKIP expression. Downregulation of RKIP expression was shown to correlate with the incidence and development of gastric carcinomas. Thus, abnormal promoter methylation of RKIP may be a valuable biomarker for estimating gastric carcinoma prognosis.

\section{Introduction}

The development of gastric carcinoma is associated with the abnormal expression of multiple genes (1-3), and mechanisms of abnormal gene expression include genetic alterations and epigenetic changes (4). Epigenetic changes are crucial to initiating carcinogenesis (5). DNA methylation is an important type of epigenetic change (5). DNA methylation occurs primarily in $\mathrm{CpG}$ islands within gene promoters, resulting in transcriptional inactivation and gene silencing (6). DNA methylation of multiple genes is associated with the development of gastric carcinoma (7-9).

Raf kinase inhibitory protein (RKIP) encodes a protein that inhibits Raf-1 (a serine/threonine kinase)-mediated phosphorylation, and thereby the activation of MEK-1 [a mitogen-activated protein (MAP) kinase kinase that specifically phosphorylates the regulatory threonine and tyrosine residues present in MAP kinases] by Raf-1 (10). The antimetastatic function of RKIP was first identified by Fu et al (11), and since then RKIP expression has been investigated in numerous cancer types. Downregulation of RKIP expression has been observed in a number of types of human cancer, including breast carcinoma (12), acute myeloid leukemia (13), colorectal carcinoma (14) and melanomas (15). These observations revealed that the expression of RKIP is lower in metastatic tissue compared with nonmetastatic tissue and correlated with decreased survival times, indicating that RKIP may be a prognostic marker of human cancer (16-18). The mechanisms underlying abnormal RKIP expression in gastric carcinoma remain largely unknown. Guo et al (19) demonstrated that 
RKIP methylation has an important role in the downregulation of RKIP expression in gastric cardia adenocarcinoma; however, the study did not include other subtypes of gastric adenocarcinoma. To further investigate the mechanism of RKIP expression in gastric cancer, the present study included all surgical subtypes of gastric adenocarcinoma.

In the present study, the rate of RKIP expression was determined in gastric adenocarcinoma tissues and adjacent mucosa tissues. Furthermore, the correlation between RKIP promoter methylation and RKIP expression was analyzed. The aim of the present study was to determine whether RKIP methylation may represent a valuable biomarker for estimating gastric carcinoma prognosis, and thus, may be a novel target for gastric adenocarcinoma therapy.

\section{Materials and methods}

Patients and tissue samples. A total of 135 patients who underwent surgical resections for primary sporadic gastric carcinoma at the First Affiliated Hospital of Xinxiang Medical University (Weihui, China) between January 2004 and December 2007 were recruited for the study. None of the patients had received preoperative chemotherapy or radiotherapy. In total, 92 males and 43 females (mean age, 58.32 years; range, 28-73 years) were included. The samples obtained included 23 cases of early gastric cancer and 112 cases of advanced gastric cancer, which constituted 31 cases of well-differentiated cancer, 48 cases of moderately differentiated cancer and 56 cases of poorly differentiated cancer. A total of 84 samples were obtained from patients with positive lymph node metastases, while 51 samples were obtained from patients with negative lymph node metastases. All the tumors were adenocarcinomas and were graded according to the World Health Organization criteria (20). Patients were followed-up until mortality or the end of the study (November 30, 2012); the mean postoperative follow-up duration was $50.76 \pm 29.70$ months. The clinical and pathological characteristics of the samples obtained are shown in Table I. The study was approved by the Ethics Committee of Xinxiang Medical University and written informed consent was provided by the patient's family,

DNA extraction and sodium bisulfite modification. Genomic DNA was isolated using a DNA extraction kit (Tiangen Biotech Co., Ltd. (Beijing, China). The total DNA content and purity $\left(\mathrm{A}_{260} / \mathrm{A}_{280}>1.8\right)$ was measured using an ultraviolet spectrophotometer, and DNA integrity was analyzed using agarose electrophoresis with a gel image analysis system (Syngene, Cambridge, UK). Bisulfite conversion was performed using $1 \mu \mathrm{g}$ genomic DNA and the CpGenome DNA Modification kit (Intergen, Purchase, NY, USA).

Methylation-specific polymerase chain reaction (PCR). Methylation-specific PCR (MSP) was used to analyze the methylation status of RKIP. RKIP primers were designed in accordance with the study by Al-Mulla et al (21) (Table II). MSP was performed in $25-\mu 1$ reaction volumes. Following predegeneration at $95^{\circ} \mathrm{C}$ for $10 \mathrm{~min}$, a total of 40 cycles of $45 \mathrm{sec}$ at $95^{\circ} \mathrm{C}, 30 \mathrm{sec}$ at $53^{\circ} \mathrm{C}$ and $30 \mathrm{sec}$ at $72^{\circ} \mathrm{C}$ were completed, followed by a $10 \mathrm{~min}$ final extension at $72^{\circ} \mathrm{C}$. The PCR products were subsequently observed using $2.0 \%$
Table I. Clinical and pathological characteristics of gastric adenocarcinoma cases.

\begin{tabular}{|c|c|}
\hline Variable & Cases, n $(\%)$ \\
\hline \multicolumn{2}{|l|}{ Age, years } \\
\hline$\geq 60$ & $72(53.3)$ \\
\hline$<60$ & $63(46.7)$ \\
\hline \multicolumn{2}{|l|}{ Gender } \\
\hline Male & $92(68.1)$ \\
\hline Female & 43 (31.9) \\
\hline \multicolumn{2}{|c|}{ Tumor size, mm } \\
\hline$\geq 50$ & $57(42.2)$ \\
\hline$<50$ & $78(57.8)$ \\
\hline \multicolumn{2}{|c|}{ Tumor differentiation } \\
\hline Well & $31(23.0)$ \\
\hline Moderate & $48(35.6)$ \\
\hline Poor & $56(41.5)$ \\
\hline \multicolumn{2}{|c|}{ Pathological staging } \\
\hline Early & $23(17.0)$ \\
\hline Advanced & $112(83.0)$ \\
\hline \multicolumn{2}{|l|}{ Stage } \\
\hline I & $33(24.4)$ \\
\hline II & $44(32.6)$ \\
\hline III & $49(36.3)$ \\
\hline IV & $9(6.7)$ \\
\hline \multicolumn{2}{|c|}{ Lymph node metastasis } \\
\hline Negative & $51(37.8)$ \\
\hline Positive & $84(62.2)$ \\
\hline
\end{tabular}

agarose gel electrophoresis. A water blank was used as a negative control and placental DNA methylated by $\mathrm{CpG}$ methyltransferase (M.SssI), in accordance with the manufacturer's instructions (New England Biolabs, Inc., Beverly, MA, USA), was used as a positive control.

Immunohistochemical staining. Full tissue sections of 135 paraffin-embedded gastric adenocarcinomas were processed for immunohistochemical staining of RKIP. Specimens were fixed in $4 \%$ paraformaldehyde and embedded in paraffin. A 4- $\mu \mathrm{m}$ section from each patient was cut, dried, dewaxed and rehydrated, prior to treatment with $3 \%$ hydrogen peroxide solution for $10 \mathrm{~min}$ and microwave treatment in citrate buffer $(\mathrm{pH} 6.0)$ at $95^{\circ} \mathrm{C}(3 \times 10 \mathrm{~min})$. Nonspecific binding was blocked by treating the slides with $10 \%$ normal goat serum for $15 \mathrm{~min}$. The slides were then incubated with rabbit polyclonal antibodies against human RKIP (1:200; Beijing Sequoia Jinqiao Company, Beijing, China) for $20 \mathrm{~min}$ at room temperature. Next, the slides were incubated with horseradish peroxidase-labeled streptavidin solution for $20 \mathrm{~min}$ at room temperature. Color development was achieved using a 3,3'-diaminobenzidine solution. The slides were counterstained with $1 \%$ Meyer's hematoxylin. As a negative control for RKIP staining, tissue sections were treated with phosphate-buffered saline instead of rabbit polyclonal antibodies against human 
Table II. RKIP gene methylation specific PCR primers sequences and temperatures.

\begin{tabular}{llcc}
\hline RKIP & \multicolumn{1}{c}{ Sequences } & Length, bp & Tm, ${ }^{\circ} \mathrm{C}$ \\
\hline Unmethylated & & & 53 \\
Sense primer & 5'-TTTAGTGATATTTTTTGAGATATGA-3' & 205 & \\
Antisense primer & 5'-CACTCCCTAACCTCTAATTAACCAA-3' & & 53 \\
Methylated & 5'-TTTAGCGATATTTTTTGAGATACGA-3' & 204 & \\
Sense primer & 5'-GCTCCCTAACCTCTAATTAACCG-3' & & \\
Antisense primer &
\end{tabular}

RKIP, Raf kinase inhibitory protein; Tm, melting temperature; PCR, polymerase chain reaction.

Table III. Methylation status and protein expression of RKIP in gastric adenocarcinoma tissues and corresponding normal tissues.

\begin{tabular}{|c|c|c|c|c|c|c|c|}
\hline \multirow[b]{2}{*}{ Tissues } & \multirow[b]{2}{*}{ Cases, $\mathrm{n}$} & \multicolumn{2}{|c|}{ Methylation frequency, $\mathrm{n}$} & \multirow[b]{2}{*}{ P-value } & \multicolumn{2}{|c|}{ Protein expression, $\mathrm{n}$} & \multirow[b]{2}{*}{ P-value } \\
\hline & & Positive & Negative & & Positive & Negative & \\
\hline Gastric tumor & 135 & 66 & 69 & $<0.001$ & 58 & 77 & $<0.001$ \\
\hline Normal & 135 & 7 & 128 & $<0.001$ & 123 & 12 & $<0.001$ \\
\hline
\end{tabular}

RKIP, Raf kinase inhibitory protein.

A

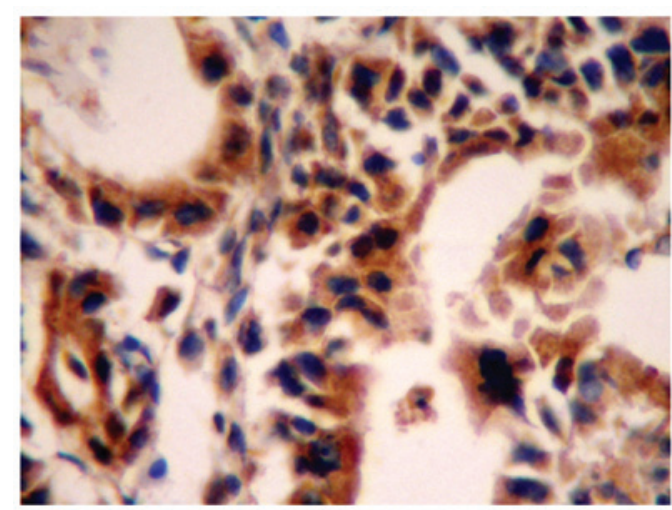

B

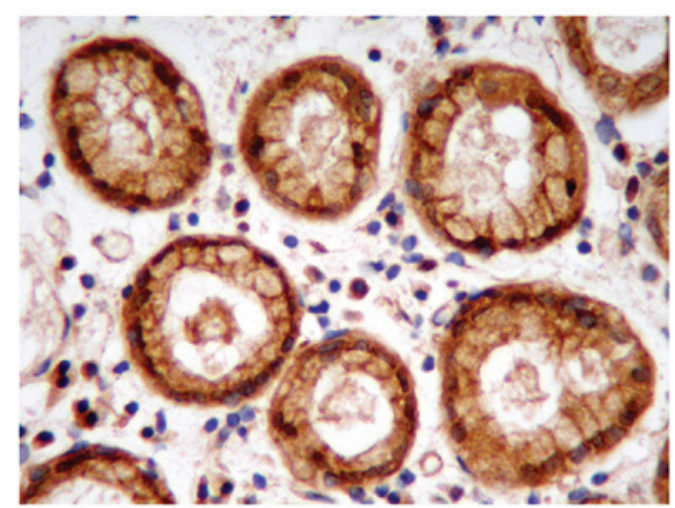

Figure 1. Positive immunohistochemical staining of RKIP in (A) gastric adenocarcinoma tissues and (B) normal tissues (magnification, $\mathrm{x}$ 400). RKIP, Raf kinase inhibitory protein.

RKIP. The positive control was a normal gastric mucosa tissue known to express RKIP. Water was used instead of the primary antibody as a negative control.

Statistical analysis. All statistical analyses were performed using SPSS software version 17.0 (SPSS, Inc., Chicago, IL, USA). The $\chi^{2}$ test and two-tailed Fisher's exact test were used to determine the correlation between RKIP promoter methylation and expression with clinicopathological parameters. The correlation between RKIP promoter methylation and expression was assessed using the Spearman's rank test. Kaplan-Meier analysis was used to estimate survival as a function of time, and survival differences were analyzed using the log-rank test. Multivariate analysis of the prognostic factors was performed using the Cox proportional hazards model. $\mathrm{P}<0.05$ was considered to indicate a statistically significant difference.

\section{Results}

RKIP promoter methylation and protein expression in normal gastric tissue and gastric adenocarcinomas. Using the MSP method and immunohistochemical staining, RKIP promoter methylation and expression were detected in 135 pairs of gastric adenocarcinoma tissues and their matched adjacent tissues. The incidence of RKIP promoter methylation in the gastric adenocarcinoma tissues $(48.9 \%)$ was significantly higher compared with the adjacent mucosa tissues $(5.2 \%$; $\mathrm{P}<0.05)$. RKIP protein expression was largely localized in the cytoplasm of the normal glands. In a few cells, low levels of RKIP expression were detected in the cell membranes (Fig. 1). The incidence of RKIP protein expression in the tumor tissues $(43.0 \%, 58 / 135)$ was significantly lower compared with the adjacent mucosa tissues $(91.1 \%, 123 / 135$; $\mathrm{P}<0.05$; Table III). 
Table IV. Association between RKIP methylation status and RKIP protein expression.

\begin{tabular}{lccc}
\hline & \multicolumn{2}{c}{ Protein expression of RKIP, $\mathrm{n}$} & \\
\cline { 2 - 4 } Methylation status of RKIP & Positive & Negative & $<$ \\
\hline Methylated & 9 & 57 & $<0.001$ \\
Unmethylated & 49 & 20 & - \\
\hline
\end{tabular}

RKIP, Raf kinase inhibitory protein.

Table V. Correlation between clinicopathological parameters with the methylation status and protein expression of RKIP.

\begin{tabular}{|c|c|c|c|c|c|}
\hline Variable & Cases, n & $\begin{array}{c}\text { Positive RKIP } \\
\text { methylation, n (\%) }\end{array}$ & P-value & $\begin{array}{l}\text { Positive RKIP protein } \\
\text { expression, n }(\%)\end{array}$ & P-value \\
\hline \multicolumn{6}{|l|}{ Age, years } \\
\hline$\geq 60$ & 72 & $33(45.8)$ & \multirow[t]{2}{*}{0.448} & $34(47.2)$ & \multirow[t]{2}{*}{0.285} \\
\hline$<60$ & 63 & $33(52.4)$ & & $24(38.1)$ & \\
\hline \multicolumn{6}{|l|}{ Gender } \\
\hline Male & 92 & $43(46.7)$ & \multirow[t]{2}{*}{0.465} & $42(45.7)$ & \multirow[t]{2}{*}{0.356} \\
\hline Female & 43 & $23(53.5)$ & & $16(37.2)$ & \\
\hline \multicolumn{6}{|c|}{ Tumor size, mm } \\
\hline$\geq 50$ & 57 & $33(57.9)$ & \multirow[t]{2}{*}{0.074} & $19(33.3)$ & \multirow[t]{2}{*}{0.053} \\
\hline$<50$ & 78 & $33(42.3)$ & & $39(50.0)$ & \\
\hline \multicolumn{6}{|c|}{ Tumor differentiation } \\
\hline Well & 31 & $9(29.0)$ & \multirow[t]{3}{*}{0.037} & $18(58.1)$ & \multirow[t]{3}{*}{0.005} \\
\hline Moderate & 48 & $25(52.1)$ & & $25(52.1)$ & \\
\hline Poor & 56 & $32(57.1)$ & & $15(26.8)$ & \\
\hline \multicolumn{6}{|c|}{ Pathological staging } \\
\hline Early & 23 & $6(26.1)$ & \multirow[t]{2}{*}{0.016} & $15(65.2)$ & \multirow[t]{2}{*}{0.018} \\
\hline Advanced & 112 & $60(53.6)$ & & $43(38.4)$ & \\
\hline \multicolumn{6}{|l|}{ Stage } \\
\hline I & 33 & $10(30.3)$ & \multirow[t]{4}{*}{0.015} & $22(66.7)$ & \multirow[t]{4}{*}{0.012} \\
\hline II & 44 & $19(43.2)$ & & $17(38.6)$ & \\
\hline III & 49 & $31(63.3)$ & & $17(34.7)$ & \\
\hline IV & 9 & $6(66.7)$ & & $2(22.2)$ & \\
\hline \multicolumn{6}{|c|}{ Lymph node metastasis } \\
\hline Negative & 51 & $19(37.3)$ & \multirow[t]{2}{*}{0.035} & $28(54.9)$ & \multirow[t]{2}{*}{0.029} \\
\hline Positive & 84 & $47(56.0)$ & & $30(35.7)$ & \\
\hline
\end{tabular}

RKIP, Raf kinase inhibitory protein.

A total of nine gastric adenocarcinoma cases exhibited positive RKIP expression, while the remaining 57 cases of gastric adenocarcinoma with negative RKIP expression exhibited RKIP promoter methylation. These observations indicated that low RKIP expression was associated with RKIP promoter methylation $(\mathrm{P}<0.01$; Table IV).

Correlation with clinicopathological parameters. Associations between clinicopathological parameters with the methylation status and protein expression of RKIP are presented in Table V. RKIP promoter methylation was shown to significantly corre- late with the pathological staging, tumor differentiation, Union for International Cancer Control (UICC) stage and lymph node metastasis $(\mathrm{P}<0.05)$. No statistically significant correlations were observed between RKIP promoter methylation and age or gender $(\mathrm{P}>0.05)$. RKIP expression was detected in 58.1, 52.1 and $26.8 \%$ of cases in the well-differentiated, moderately differentiated and poorly differentiated groups, respectively $(\mathrm{P}<0.05)$. RKIP expression was demonstrated to be associated with pathological staging, UICC stage and lymph node metastasis $(\mathrm{P}<0.05)$, but no correlations were observed with regard to age or gender $(\mathrm{P}>0.05)$. 
Table VI. Univariate and multivariate analyses of the disease-free survival rate.

\begin{tabular}{|c|c|c|c|c|c|c|}
\hline \multirow[b]{2}{*}{ Variable } & \multirow[b]{2}{*}{ Cases, $\mathrm{n}$} & \multicolumn{2}{|c|}{ Univariate analysis } & \multicolumn{3}{|c|}{ Multivariate analysis } \\
\hline & & $\begin{array}{l}\text { Five-year overall } \\
\text { survival rate }(\%)\end{array}$ & P-value & Relative risk & $95 \% \mathrm{CI}$ & P-value \\
\hline \multicolumn{7}{|l|}{ Age, years } \\
\hline$\geq 60$ & 72 & 45.8 & 0.352 & - & - & - \\
\hline$<60$ & 63 & 41.3 & - & - & - & - \\
\hline \multicolumn{7}{|l|}{ Gender } \\
\hline Male & 92 & 43.5 & 0.690 & - & - & - \\
\hline Female & 43 & 44.2 & - & - & - & - \\
\hline \multicolumn{7}{|l|}{ Tumor size, $\mathrm{mm}$} \\
\hline$\geq 50$ & 57 & 33.3 & 0.007 & - & - & - \\
\hline$<50$ & 78 & 51.3 & - & - & - & - \\
\hline \multicolumn{7}{|c|}{ Tumor differentiation } \\
\hline Well & 31 & 54.8 & 0.013 & - & - & - \\
\hline Moderate & 48 & 45.8 & - & - & - & - \\
\hline Poor & 56 & 35.7 & - & - & - & - \\
\hline \multicolumn{7}{|c|}{ Pathological staging } \\
\hline Early & 23 & 87.0 & $<0.001$ & - & - & - \\
\hline Advanced & 112 & 34.8 & - & - & - & - \\
\hline \multicolumn{7}{|l|}{ Stage } \\
\hline I & 33 & 81.8 & $<0.001$ & 1.700 & $1.287-2.244$ & $<0.001$ \\
\hline II & 44 & 45.5 & - & - & - & - \\
\hline III & 49 & 24.5 & - & - & - & - \\
\hline IV & 9 & 0 & - & - & - & - \\
\hline \multicolumn{7}{|c|}{ Lymph node metastasis } \\
\hline Negative & 51 & 70.6 & $<0.001$ & 0.596 & $0.372-0.956$ & 0.032 \\
\hline Positive & 84 & 27.4 & - & - & - & - \\
\hline \multicolumn{7}{|c|}{ RKIP methylation status } \\
\hline Methylated & 66 & 27.3 & $<0.001$ & 1.602 & $1.038-2.473$ & 0.033 \\
\hline Unmethylated & 69 & 59.4 & - & - & - & - \\
\hline \multicolumn{7}{|c|}{ Protein expression of RKIP } \\
\hline Negative & 77 & 29.9 & $<0.001$ & - & - & - \\
\hline Positive & 58 & 62.1 & - & - & - & - \\
\hline
\end{tabular}

RKIP, Raf kinase inhibitory protein; CI, confidence interval.
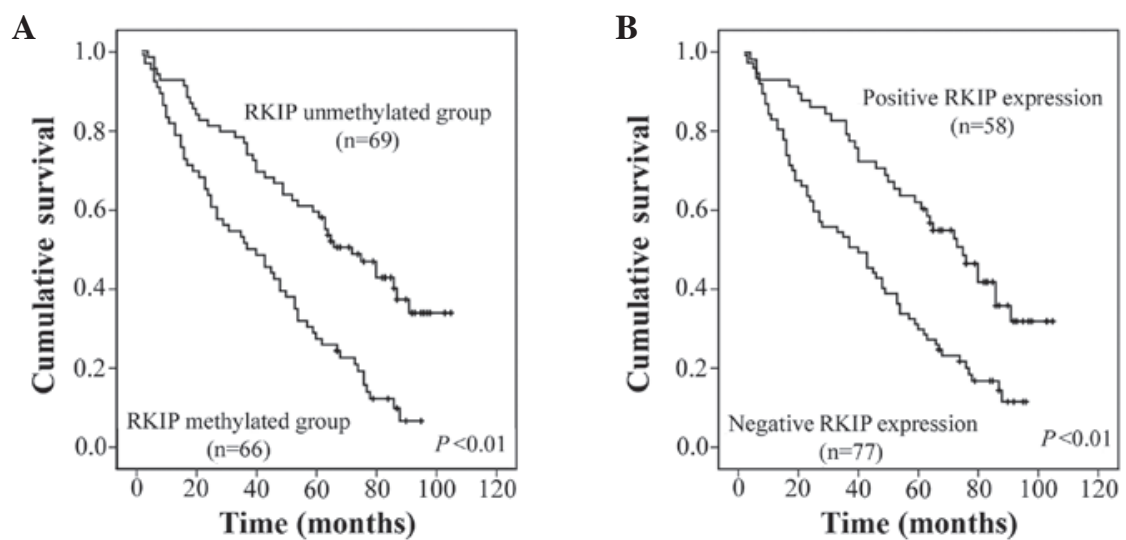

Figure 2. Comparison of the overall survival rates of gastric carcinoma patients with (A) RKIP promoter unmethylation vs. RKIP promoter methylation and (B) positive expression of RKIP tumors vs. negative expression of RKIP tumors. RKIP, Raf kinase inhibitory protein. 
Correlation with patient survival rates. The five-year overall survival rates of the patients was $43.7 \%$, and the median survival time was $53 \pm 5$ months. The five-year overall survival rates of patients with RKIP promoter methylation were significantly lower compared with the patients with unmethylated RKIP promoters $(\mathrm{P}<0.001)$. Methylation of RKIP was shown to be inversely correlated with the survival of patients with gastric adenocarcinoma (Fig. 2A). The five-year overall survival rates of patients with RKIP-negative tumors were significantly lower compared with those in the RKIP-positive group ( $\mathrm{P}=0.001)$. RKIP expression positively correlated with the survival rate of gastric adenocarcinoma patients (Fig. 2B). Furthermore, in the multivariate analysis, potential prognosis factors, including lymph node metastasis, UICC-stage and RKIP promoter methylation, were included in the Cox proportional hazards model. The results indicated that in addition to UICC-stage staging and lymph node metastasis, the RKIP promoter methylation status is an independent prognostic factor $(\mathrm{P}=0.033$; Table VI).

\section{Discussion}

RKIP plays an important role in cancer via the regulation of apoptosis induced by chemotherapeutic agents or immune-mediated stimuli, as well as functioning as a metastasis suppressor protein (22). The gene encoding RKIP is located on human chromosome $12 \mathrm{q} 24.23$, and is transcribed into a 1,507-bp mRNA product containing four exons; the final protein product is 187 amino acids long. Downregulated RKIP expression activates the Raf-1/MEK/extracellular signal-regulated kinase and nuclear factor- $\kappa \mathrm{B}$ signaling pathways, which enhances cell proliferation and invasion, inhibiting apoptosis and eventually leading to cancer (23).

Chatterjee et al (22) demonstrated that cytoplasmic RKIP was expressed at low levels in gastric cancer and directly correlated with the rate of patient survival. Similarly, in the present study, RKIP expression was demonstrated to be significantly decreased in gastric adenocarcinoma tissue, and an association with poor patient prognosis was observed. However, little information is available with regard to the mechanism responsible for RKIP downregulation in gastric cancer.

DNA methylation is one of the best-characterized epigenetic modifications and has been implicated in numerous biological processes, including transposable element silencing, genomic imprinting and $\mathrm{X}$ chromosome inactivation (24). Guo et al (25) demonstrated that RKIP promoter methylation is a major reason for the downregulation of RKIP expression. In addition, RKIP methylation was reported to lead to the downregulation of RKIP expression in gastric cardia adenocarcinoma (19). Al-Mulla et al (21) demonstrated that RKIP promoter methylation is a major mechanism by which RKIP expression is silenced in colorectal cancer. However, there are other mechanisms responsible for the downregulation of RKIP expression in hepatocellular carcinoma and prostate cancer. Poma et al (26) demonstrated that DNA methylation was unable to explain the low levels of RKIP expression observed in hepatocellular carcinoma. Furthermore, Martinho et al (27) demonstrated that low RKIP expression was not the result of promoter methyla- tion in prostate cancer. However, in the present study, RKIP promoter methylation in gastric carcinoma was shown to be associated with the expression of RKIP protein; thus, was an independent prognostic factor.

In conclusion, the results of the present study demonstrated that abnormal methylation of RKIP is a crucial mechanism underlying the downregulation of RKIP expression in gastric adenocarcinoma. In addition, abnormal RKIP methylation was demonstrated to be directly associated with the progression and poor prognosis of gastric adenocarcinoma. However, the mechanisms underlying RKIP suppression of tumor cell migration and the promotion of gastric carcinogenesis by abnormal RKIP methylation remain unknown; thus, further investigation is required.

\section{References}

1. Begnami MD, Fukuda E, Fregnani JH, et al: Prognostic implications of altered human epidermal growth factor receptors (HERs) in gastric carcinomas: HER2 and HER 3 are predictors of poor outcome. J Clin Oncol 29: 3030-3036, 2011.

2. Zhang L, Xu Z, Xu X, et al: SALL4, a novel marker for human gastric carcinogenesis and metastasis. Oncogene: Nov 25, 2013 (Epub ahead of print).

3. Tang H, Deng M, Tang Y, et al: miR-200b and miR-200c as prognostic factors and mediators of gastric cancer cell progression. Clin Cancer Res 19: 5602-5612, 2013.

4. You JS and Jones PA: Cancer genetics and epigenetics: two sides of the same coin? Cancer Cell 22: 9-20, 2012.

5. Baylin SB and Jones PA: A decade of exploring the cancer epigenome - biological and translational implications. Nat Rev Cancer 11: 726-734, 2011.

6. Taby R and Issa JP: Cancer epigenetics. CA Cancer J Clin 60: 376-392, 2010

7. Hu X, Sui X, Li L, et al: Protocadherin 17 acts as a tumour suppressor inducing tumour cell apoptosis and autophagy, and is frequently methylated in gastric and colorectal cancers. J Pathol 229: 62-73, 2013.

8. Yu J, Liang QY, Wang J, et al: Zinc-finger protein 331, a novel putative tumor suppressor, suppresses growth and invasiveness of gastric cancer. Oncogene 32: 307-317, 2013.

9. Du W, Wang S, Zhou Q, et al: ADAMTS9 is a functional tumor suppressor through inhibiting AKT/mTOR pathway and associated with poor survival in gastric cancer. Oncogene 32: 3319-3328, 2013.

10. Yeung K, Seitz T, Li S, et al: Suppression of Raf-1 kinase activity and MAP kinase signalling by RKIP. Nature 401: 173-177, 1999.

11. Fu Z, Smith PC, Zhang L, et al: Effects of raf kinase inhibitor protein expression on suppression of prostate cancermetastasis. J Natl Cancer Inst 95: 878-889, 2003.

12. Al-Mulla F, Bitar MS, Thiery JP, et al: Clinical implications for loss or diminution of expression of Raf-1 kinase inhibitory protein and its phosphorylated form in ductal breast cancer. Am J Cancer Res 3: 446-464, 2013.

13. Zebisch A, Wölfler A, Fried I, et al: Frequent loss of RAF kinase inhibitor protein expression in acute myeloid leukemia. Leukemia 26: 1842-1849, 2012.

14. Al-Mulla F, Hagan S, Behbehani AI, et al: Raf kinase inhibitor protein expression in a survival analysis of colorectal cancer patients. J Clin Oncol 24: 5672-5679, 2006.

15. Das SK, Bhutia SK, Sokhi UK, et al: Raf kinase inhibitor RKIP inhibits MDA-9/syntenin-mediated metastasis in melanoma. Cancer Res 72: 6217-6226, 2012.

16. Zlobec I, Baker K, Minoo P, et al: Node-negative colorectal cancer at high risk of distant metastasis identified by combined analysis of lymph node status, vascular invasion, and Raf-1 kinase inhibitor protein expression. Clin Cancer Res 14: 143-148, 2008.

17. Beach S, Tang H, Park S, et al: Snail is a repressor of RKIP transcription in metastatic prostate cancer cells. Oncogene 27: 2243-2248, 2008.

18. Al-Mulla F, Bitar MS, Al-Maghrebi M, et al: Raf kinase inhibitor protein RKIP enhances signaling by glycogen synthase kinase-3 $\beta$. Cancer Res 71: 1334-1343, 2011. 
19. Guo W, Dong Z, Guo Y, et al: Aberrant methylation and loss expression of RKIP is associated with tumor progression and poor prognosis in gastric cardia adenocarcinoma. Clin Exp Metastasis 30: 265-275, 2013.

20. Hamilton SR and Aaltonen LA (eds): Pathology and genetics of tumours of the digestive system. In: World Health Organization Classification of Tumours. IARC Press, Lyon, 2000.

21. Al-Mulla F, Hagan S, Al-Ali W, et al: Raf kinase inhibitor protein: mechanism of loss of expression and association with genomic instablility. J Clin Pathol 61: 524-529, 2008.

22. Chatterjee D, Sabo E, Tavares R and Resnick MB: Inverse association between Raf kinase inhibitory protein and signal transducers and activators of transcription 3 expression in gastric adenocarcinoma patients: implications for clinical outcome. Clin Cancer Res 14: 2994-3001, 2008.
23. Hsu YL, Chen CY, Lin IP, et al: 4-Shogaol, an active constituent of dietary ginger, inhibits metastasis of MDA-MB-231 human breast adenocarcinoma cells by decreasing the repression of NF-kB/Snail on RKIP. J Agric Food Chem 60: 852-861, 2012.

24. Wu SC and Zhang Y: Active DNA demethylation: many roads lead to Rome. Nat Rev Mol Cell Biol 11: 607-620, 2010.

25. Guo W, Dong Z, Lin X, et al: Decreased expression and aberrant methylation of Raf kinase inhibitory protein gene in esophageal squamous cell carcinoma. Cancer Invest 30: 703-711, 2012.

26. Poma P, Labbozzetta M, Vivona N, et al: Analysis of possible mechanisms accounting for Raf-1 kinase inhibitor protein downregulation in hepatocellular carcinoma. OMICS 16: 579-588, 2012.

27. Martinho O, Gouveia A, Silva P, et al: Loss of RKIP expression is associated with poor survival in GISTs. Virchows Arch 455: $277-284,2009$ 